\title{
Investigation of distinctive characteristics of children with specific learning disorder and borderline intellectual functioning
}

\author{
Selcuk Ozkan1, Koray Kara², Mahmoud Almbaideen³, Mehmet Ayhan Congologlu22 \\ 1 Gulhane Medical Faculty, Gulhane Training and Research Hospital, Department of Child and Adolescent Psychiatry, Etlik, Kecioren, Ankara, Turkey. \\ 2 Gulhane Askeri Tip Akademisi Ringgold, Gulhane Military Medical Academy, Department of Child and Adolescent Psychiatry, Etlik, Kecioren, Ankara, Turkey. \\ 3 Private Madalyon Psychiatry Center - Child and Adolescent Psychiatry, Ankara, Turkey.
}

Received: $1 / 10 / 2017$ - Accepted: $11 / 14 / 2017$

DOI: 10.1590/0101-60830000000145

\begin{abstract}
Background: Borderline intelligence function (BIF) and specific learning disorder (SLD) are common diagnoses in children who are brought up for learning problems and school failure. Objective: The aim of our study was to determine whether there were distinctive aspects of cognitive testing routinely used in evaluating SLD and BIF and investigate emotion regulation skills and minor neurologic symptoms. Method: Sixty children (30 SLD and 30 BIF) who are currently attending primary school are selected for study. Visual Aural Digit Span Test - Form B, Gessel Figure Drawing Test, Bender Gestalt Visual Motor Perception Test, WISC-R, Emotion Regulation Scale (ERS) and Neurological Evaluation Scale (NES) was administered. Results: There was no statistically significant difference between groups in cognitive tests. The emotional regulation ability measured by the emotional regulation subscale was better in the SLD group than the BIF group ( $\mathrm{p}=0.014)$. In the NES, sensory integration $(\mathrm{p}=0.008)$, motor coordination $(\mathrm{p}=0.047)$ and other $(\mathrm{p}<0.001)$ subscales showed higher scores in the BIF group. Discussion: It has been shown that cognitive tests don't have distinguishing features in the evaluation of SLD and BIF. Emotion regulation subscale score of ERS and sensory integration, motor coordination, and total scores of NES can be used in both discrimination of groups.
\end{abstract}

Ozkan S et al. / Arch Clin Psychiatry. 2018;45(1):1-6

Keywords: Specific learning disorder, borderline intellectual functioning, cognitive functions, minor neurological symptoms.

\section{Introduction}

Learning problems and school failure are common causes of child and adolescent psychiatric outpatient visits, especially in primary school age. Borderline intelligence function (BIF) and specific learning disorder (SLD) are common diagnoses in children who are brought up for this reason.

In a study conducted in Turkey "school failure" was the third most common cause of admission in all children and adolescents, and was the most frequent cause of admission in the age group 6-11. In a study examining the distribution of diagnoses in all children and adolescents who applied to a Child and Adolescent Psychiatry Unit in Turkey between January 2012 and April 2013, 2.2\% of the diagnoses were BIF, $1.8 \%$ were SLD in boys and $2.9 \%$ were BIF and $2.3 \%$ were SLD in girls ${ }^{2}$. In another study which was performed in GATA Child and Adolescent Psychiatry Department which was examining the distribution of the diagnosis, the rate of SLD was $8.9 \%$ and the rate of BIF was $2.1 \%^{3}$.

Despite the fact that they are both frequent reasons for referral, there are frequent difficulties in discrimination between these two diagnoses. The common feature of these two groups of diagnoses is that they usually do not have a significant set of symptoms in the pre-school period, so they do not cause problems in the preschool period, and therefore the reasons for initial admission of families are often reading and writing problems. The existing scales developed to distinguish these diagnoses which have clinically similar symptomatology are inadequate in most cases and may lead to diagnostic confusion. There are no studies in which a comparison of these two diagnoses is made and the differences to be used in differential diagnosis are identified.

The SLD is a relatively more studied diagnosis. There are studies showing that the accompanying problems in SLD are more frequent, especially in neurological and psychological and emotional problems than in normal children. Similar results were obtained by comparing with the control group in studies conducted with BIF even though there are very few. However, when the literature is searched, these two distinctions are unprecedented in these respects.
The BIF is used to describe situations where the IQ score from standard intelligence tests is not low enough to be called mental retardation, but below average intelligence (usually between 70 and 85). BIF is not a disease, syndrome or disorder. It is a neurodevelopmental syndrome and neurodevelopmental syndromes are formed by heterogeneous grouping of disorders and diseases, or they are a variant of normal. They are expected to have limitations according to the normal intelligence group in all areas of functioning, and to be in better condition compared to the group with mental retardation ${ }^{4}$. There are only a few number of studies on BIF. Current studies indicate about $13 \%-15 \%$ incidence rate in the population ${ }^{5-7}$.

In the Diagnostic and Statistical Manual of Mental Disorders - Fourth Edition (DSM-IV-TR), SLD was diagnosed when the individual's (that have normal or above normal level of intelligence) reading, written expression or mathematics levels found below from expected for his or her age and level of intelligence obtained in standardized intelligence tests. In the DSM-IV-TR, SLD was classified as Reading Disorder, Math Disorder, Written Expression Disorder and Learning Disorder, Not Otherwise Specified. In DSM-5, separate classification of SLD diagnosis is abolished and SLD is defined as a single diagnostic category with "specifiers" to characterize the specific manifestations of learning difficulties at the time of assessment in three major academic domains, namely; reading, writing, mathematics (e.g., SLD with impairment in reading) ${ }^{8,9}$.

Due to the fact that, SLD does not have clinically defined clear borders and the use of different cut-off points in the studies, the data about the frequency of SLD may be different. Surveys conducted in this area reveal a wide range of prevalence, from $1 \%$ to $30 \%{ }^{10}$. In an epidemiological study, Lewis et al found that $1.3 \%$ of children had arithmetic difficulties, $2.3 \%$ had both arithmetic and reading difficulties and $3.9 \%$ had reading difficulties ${ }^{11}$. Although different ratios are reported in the studies for gender distribution, the general opinion is that the male/female ratio is between $1.39-3.19$ in the SLD ${ }^{12}$.

In this study, it was aimed to determine whether there are distinctive aspects of the cognitive tests used in routine evaluation 
of these two disease groups in the clinical sample, to investigate emotional competence in patient groups and to compare the presence of minor neurological symptoms (MNS).

Minor neurological symptoms has been described as abnormal performance in motor or sensory neurological examination without a focal lesion ${ }^{13}$. In the literature, MNS have different nomenclature such as minor neurological deficits, soft neurological signs, neurological minor signs.

Minor neurological symptoms include poor motor coordination, sensory perceptual difficulties, difficulties in organizing complex motor tasks ${ }^{14}$. There are many studies that relate MNS with psychiatric diseases, behavioral problems, and academic difficulties. In addition, there are data indicating that neurological symptoms are present in varying proportions in healthy individuals ${ }^{15,16}$.

Emotion regulation has been the subject of many different studies in child and adolescent psychiatry. In a study examining the effect of emotion regulation skill on academic achievement, 325 children receiving preschool education were evaluated. The assessment was made after the children's intelligence scores were equalized. It was found that there was a significant positive correlation between academic achievement and emotional regulation skill ${ }^{17}$. In another study, the children with specific speech impairment are reported to have worse emotion regulation skills than those without. In addition, emotion regulation problems were found to be higher in girls than in boys ${ }^{18}$.

\section{Materials and methods}

This study is a cross-sectional and descriptive study carried out between May 2016 and June 2016 in Gulhane Military Medical Academy, Department of Child and Adolescent Psychiatry. The participants were 30 SLD and 30 BIF children who referred to child and adolescent outpatient clinic. Children who are still in primary school (grades 2, 3 or 4) have been selected for the reason that school failure and/or learning difficulties are being addressed in primary school. Children were included in the study after written confirmation from their parents. Diagnosis was made by a child and adolescent psychiatrist considering DSM-5 criteria. Developmental history, parental report, previous relevant diagnostic data and school information had been gathered. Following DSM-5, when classifying SLD, IQ discrepancy criterion wasn't applied. Those with clear neurological abnormalities such as epilepsy, muscular diseases, cerebral palsy, spina bifida, disabilities such as sight, hearing and major psychiatric diseases were not included in the study.

Sociodemographic data form, Emotion Regulation Scale (ERS) was filled by caregivers. Bender Gestalt Visual Motor Perception Test, Gessell Figure Drawing Test, Visual Aural Digit Span Test - Form B (GISD-B) form were conducted by clinical psychologist. Intelligence scores were obtained by applying Wechsler Intelligence Scale for Children - Revised (WISC-R) on a different day from the planned cognitive tests during the study period. The Neurological Rating Scale was administered by the clinician to the child on the same day or on different days with Cognitive Tests or WISC-R.

Ethics approval has been obtained from Ethics Committee of Gulhane Military Medical Academy (50687469-1491-351-16/16481195/06.05.2016).

\section{Sociodemographic form}

It is an interview form filled by interviewing the patient face to face, questioning the sociodemographic characteristics (such as age, sex, education status) of the participants and caregivers.

\section{Wechsler Intelligence Scale for Children - Revised form (WISC-R)}

WISC-R is a test used to determine the level of intelligence in children. WISC-R was developed in 1949 and revised in 1974, the form was created ${ }^{19}$. Turkish adaptation and standardization work was carried out in $1995^{20}$. The result of the test is a score for full Scale IQ (FSIQ) and scores for the verbal scale IQ (VSIQ) and the performance scale IQ (PSIQ). It consists of a total of 12 sub-tests. VSIQ; General Information, Comprehension, Arithmetic, Similarity, Vocabulary, Digit Span sub-tests, PSIQ contains Picture Completion, Picture Arrangement, Block Design, Object Assembly, Coding, Mazes sub-tests.

\section{Neurological Evaluation Scale (NES)}

The NES was developed in 1988 to evaluate the minor neurologic symptoms. It was first used in schizophrenic patients and in the family members and relatives of these patients to do the examinations. After the adult and child mental health field has been used in research on the subject is associated with many different diseases ${ }^{21}$. The scale consists of 26 questions. Scores of 0,1 and 2 are given for each question. High score represents the significance of the neurological symptoms, a zero score indicates that the person has passed through the examination involved in the question and there is not a problem.

\section{Emotion Regulation Scale}

It is a scale developed to assess children's emotional regulation features. The scale is filled by the child's parents or other caregivers. It consists of 24 items in total. As the score on the scale increases, the emotions are dysregulated, and as the score decreases, the emotions are well-regulated. It consists of two subscales. One of these is emotion Regulation Subscale and the other is the Lability-Negativity subscale. Emotions subscale set of 9 items, the lability-negative subscale consists of 15 items $^{22}$. Turkish validity and reliability study of the scale was made in 200923.

\section{Visual Aural Digit Span Test - Form B (GISD-B)}

GISD-B is administered to children individually. Auditory Verbal, Visual Verbal, Auditory Written and Visual Written subtests. The sum of the scores obtained from the sub-tests constitutes the test score.

Koppitz $^{24}$ developed Visual Aural Digit Span Test but it has the limitation and reduction of errors, to eliminate these GISD-B form was developed. It is a commonly used measurement tool in patient groups with academic difficulties. This test measures short-term memory capacity, sensory-motor integration and complex attention skills ${ }^{25,26}$.

\section{Bender Gestalt Visual Motor Perception Test}

It measures perceptual motor skills, perceptual motor development, and gives an indication of neurological intactness. Stimulus cards containing a specific figure are given to the child one at a time, and the child is asked to copy the figure on a blank sheet of paper. Copying figures requires fine motor skills, the ability to discriminate between visual stimuli, the capacity to integrate visual skills with motor skills, and the ability to shift attention from the original design to what is being drawn ${ }^{27}$.

\section{Gessel Figure Drawing Test}

It is a test consisting of 8 geometric shapes in total. It gives an idea about visual perceptual development and mental development. Children are asked to copy these figures drawn on A4 size paper. The figures are arranged from easy to difficult. The use of an eraser is not allowed during drawing. Evaluation is done as "successful, considered successful, considered unsuccessful, unsuccessful”.

\section{Statistical analysis}

The research data were presented in computerized mean, frequency distribution and percentages via SPSS (Statistical Package for Social Sciences). Pearson Chi-square test was used to evaluate categorical 
variables. The normal distribution of the variables was examined using the Shapiro-Wilk test. In statistical significance between two independent groups, Student T test was used for those with normal distribution, and Mann-Whitney U Test was used for those who did not. The relationship between the variables was assessed by the Spearman Correlation Test. Statistical significance level was accepted as $\mathrm{p}<0.05$.

\section{Results}

A total of 60 children with 30 SLD and 30 BIF were included in the study. There was no statistically significant difference between the groups in terms of age, gender, class, parental age, parental education status. Sociodemographic characteristics of the groups are given in Table 1.

There were no statistically significant differences between the SLD and BIF groups in terms of test performances of the Bender Gestalt and Gessell Figure Drawing Test (Table 2). The results of the WISC-R, Gessell Figure Drawing Test and Bender Gestalt test of the groups are shown in Table 2.

No statistically significant difference was found between the groups when the performances of the Visual Aural Digit Span Test - Form B (GISD-B) were evaluated. The auditory verbal and audiowritten subscale scores were not considered statistically significant [ $\mathrm{p}<0.05$ and for auditory verbal: 4 cells $(66,7 \%)$ and for auditory written: 6 cells $(75,0 \%)$ have expected count less than 5 , the number of cells count less than 5 should be less than 20\%] (Table 3).
There was no statistically significant difference between the scores of emotional adjustment scale total score and variability/negativity subscale scores among the groups. The emotional regulation ability measured by the emotion regulation subscale was found to be significantly better (lower score) in the SLD group. The ERS scores of the groups are given in Table 4.

We assessed whether there is a correlation between the emotion regulation scores and intelligence scores in the diagnostic groups. A statistically significant negative correlation was found between the emotion regulation subscale and PSIQ and FSIQ in the SLD group. There was no correlation between variability/negativity subscale and intelligence scores. In addition, there was no correlation between intelligence scores and Emotional Regulation Scale and its subscales in the BIF group (Table 5).

There was a statistically significant difference in sensory integration, motor coordination and other subscales between the SLD and BIF groups in the NES. Children with BIF were found to have more minor neurological symptom scores than those with SLD. No statistically significant difference was found between the groups for the complex motor movements subscale (Table 6).

We also assessed whether there is a correlation between MNS and intelligence scores. When the diagnostic groups were evaluated within themselves, a statistically significant negative correlation was found between the sensory integration subscale of NES and FSIQ. There were no correlations between subscales and FSIQ in the BIF cases (Table 7).

Table 1. Socio-demographic characteristics

\begin{tabular}{|c|c|c|c|c|c|}
\hline & & $\operatorname{SLD}(n=30)$ & $\operatorname{BIF}(n=30)$ & & $p$ \\
\hline Age & & $8.73 \pm 1.08$ & $8.63 \pm 1.03$ & $0.366^{* *}$ & 0.75 \\
\hline \multirow[t]{2}{*}{ Gender (n/\%) } & Male & $19(63 \%)$ & $22(73 \%)$ & \multirow[t]{2}{*}{$1.631^{*}$} & \multirow[t]{2}{*}{0.20} \\
\hline & Girl & $11(36 \%)$ & $8(26 \%)$ & & \\
\hline \multirow[t]{3}{*}{ Class (n/\%) } & $2^{\text {nd }}$ class & $8(26 \%)$ & $10(33 \%)$ & \multirow[t]{3}{*}{$0.682^{*}$} & \multirow[t]{3}{*}{0.71} \\
\hline & $3^{\text {th }}$ class & $7(23 \%)$ & $8(26 \%)$ & & \\
\hline & $4^{\text {th }}$ class & $15(50 \%)$ & $12(40 \%)$ & & \\
\hline Father's age & & $41.00 \pm 6.77$ & $39.93 \pm 6.82$ & $0.369^{* *}$ & 0.62 \\
\hline Mother's age & & $35.26 \pm 4.97$ & $34.70 \pm 6.78$ & $0.588^{* *}$ & 0.43 \\
\hline \multirow[t]{5}{*}{ Father's educational status (n) } & No education & - & - & \multirow[t]{5}{*}{$2.379^{*}$} & \multirow[t]{5}{*}{0.52} \\
\hline & \begin{tabular}{|l} 
Primary school \\
\end{tabular} & $10(33 \%)$ & $7(23 \%)$ & & \\
\hline & Middle school & $4(13 \%)$ & $8(26 \%)$ & & \\
\hline & High school & $12(40 \%)$ & $13(43 \%)$ & & \\
\hline & University & $2(6 \%)$ & $1(3 \%)$ & & \\
\hline \multirow[t]{5}{*}{ Mother's educational status ( $\mathrm{n}$ ) } & No education & $2(6 \%)$ & $5(16 \%)$ & \multirow[t]{5}{*}{$6.618^{*}$} & \multirow[t]{5}{*}{0.17} \\
\hline & \begin{tabular}{|l|} 
Primary school \\
\end{tabular} & $13(43 \%)$ & $14(46 \%)$ & & \\
\hline & Middle school & $3(10 \%)$ & - & & \\
\hline & High school & $10(33 \%)$ & $11(36 \%)$ & & \\
\hline & University & $2(6 \%)$ & - & & \\
\hline
\end{tabular}

SLD: specific learning disorder; BIF: borderline intellectual functioning; \pm : values are given as means and standard deviation. ${ }^{*} x^{2}$ : Chi Square test. ${ }^{* *}$ t: $t$ test.

Table 2. WISC-R, Gessell Figure Drawing Test and Bender Gestalt test results of the groups

\begin{tabular}{|l|c|c|c|c|}
\hline & SLD $(n=30)$ & BIF $(n=30)$ & \\
\hline WISC-R & & & \\
\hline VSIO & $84.76 \pm 7.74$ & $72.80 \pm 4.85$ & \\
\hline PSI0 & $101.83 \pm 7.87$ & $81.90 \pm 7.04$ & \\
\hline FSI0 & $92.53 \pm 5.41$ & $75.40 \pm 3.45$ & & \\
\hline Gessell Figure Drawing Test & & & & \\
\hline Successful & $8(26 \%)$ & $4(13 \%)$ & \\
\hline Considered successful & $5(16 \%)$ & $5(15 \%)$ & \\
\hline Considered unsuccessful & $3(10 \%)$ & $3(10 \%)$ & \\
\hline Unsuccessful & $14(46 \%)$ & $18(60 \%)$ & & \\
\hline Bender-Gestalt Test & $6(1-10)$ & $7(2-14)$ & & \\
\hline
\end{tabular}

WISC-R: Wechsler Intelligence Scale for Children - Revised; SLD: specific learning disorder; BIF: borderline intellectual functioning. Gessell Figure Drawing Test results are given as categorical values and Bender Gestalt test results as median, minimum and maximum. ${ }^{*} \mathrm{X}^{2}$ : Chi Square test. ${ }^{* *} \mathrm{Z}$ : Mann Whitney U. 
Table 3. GISD-B scores

\begin{tabular}{|c|c|c|c|c|}
\hline GISD-B subtests & $\begin{array}{c}\text { SLD } \\
(N=30)\end{array}$ & $\begin{array}{c}\text { BIF } \\
(\mathrm{N}=30)\end{array}$ & $x^{2}$ & $P$ \\
\hline \multicolumn{5}{|l|}{ Auditory Verbal } \\
\hline Below age and class level & $24(80 \%)$ & $30(100 \%)$ & \multirow[t]{4}{*}{6,667} & \multirow[t]{4}{*}{0.03} \\
\hline At age level & $2(6 \%)$ & - & & \\
\hline At class level & - & - & & \\
\hline At age and class level & $4(13 \%)$ & - & & \\
\hline \multicolumn{5}{|l|}{ Visual Verbal } \\
\hline Below age and class level & $25(83 \%)$ & $30(100 \%)$ & \multirow[t]{4}{*}{5,455} & \multirow[t]{4}{*}{0.06} \\
\hline At age level & $4(13 \%)$ & - & & \\
\hline At class level & $1(3 \%)$ & - & & \\
\hline At age and class level & - & - & & \\
\hline \multicolumn{5}{|l|}{ Auditory Written } \\
\hline Below age and class level & $15(50 \%)$ & $28(93 \%)$ & \multirow[t]{4}{*}{14,264} & \multirow[t]{4}{*}{0.003} \\
\hline At age level & $1(3 \%)$ & - & & \\
\hline At class level & $4(13 \%)$ & - & & \\
\hline At age and class level & $10(33 \%)$ & $2(6 \%)$ & & \\
\hline \multicolumn{5}{|l|}{ Visual Written } \\
\hline Below age and class level & $20(66 \%)$ & $26(86 \%)$ & \multirow[t]{4}{*}{3,836} & \multirow[t]{4}{*}{0.14} \\
\hline At age level & $4(13 \%)$ & $1(3 \%)$ & & \\
\hline At class level & $2(6 \%)$ & $1(3 \%)$ & & \\
\hline At age and class level & $4(13 \%)$ & $2(6 \%)$ & & \\
\hline
\end{tabular}

GISD-B: Visual Auditory Digit Test - Form B; SLD: specific learning disorder; BIF: borderline intellectual functioning.

Table 4. Emotion Regulation Scores and comparison

\begin{tabular}{|l|c|c|c|c|}
\hline & SLD $(\mathrm{n}=30)$ & $\mathrm{BIF}(\mathrm{n}=30)$ & $t$ & $P$ \\
\hline Lability/Negativity Subscale & $30.26 \pm 7.05$ & $29.66 \pm 7.44$ & -0.321 & 0.75 \\
\hline Emotion Regulation Subscale & $18.13 \pm 4.28$ & $20.93 \pm 4.30$ & -2.523 & 0.01 \\
\hline ERS total & $48.30 \pm 9.61$ & $50.60 \pm 10.13$ & -0.902 & 0.37 \\
\hline
\end{tabular}

SLD: specific learning disorder; BIF: borderline intellectual functioning. Values are given as mean and standard deviation.

Table 5. The relationship between ERS subscale scores and intelligence for those with SLD

\begin{tabular}{|l|c|c|c|c|}
\hline Intelligence Quotient & $\begin{array}{c}\text { Lability/Negativity Subscale } \\
\text { (Correlation coefficient) }\end{array}$ & $P$ & $\begin{array}{c}\text { Emotion Regulation Subscale } \\
\text { (Correlation coefficient) }\end{array}$ & $P$ \\
\hline VSIO & -0.095 & 0.47 & -0.217 & 0.11 \\
\hline PSIQ & -0.102 & 0.43 & -0.405 & 0.004 \\
\hline FSIO & -0.099 & 0.46 & -0.352 & 0.005 \\
\hline
\end{tabular}

SLD: specific learning disorder; BIF: borderline intellectual functioning; VSIQ, PSIQ, FSIQ: Verbal, Performance, Full scale intelligence quotient.

Table 6. Neurological Evaluation Scale scores

\begin{tabular}{|l|c|c|c|c|}
\hline & SLD $(n=30)$ & BIF $(n=30)$ & $Z$ & $P$ \\
\hline The sensory integration & $1.66 \pm 1.20$ & $2.82 \pm 1.65$ & -2.633 & 0.008 \\
\hline Motor coordination & $0.62 \pm 0.71$ & $1.21 \pm 1.10$ & -1.985 & 0.047 \\
\hline Complex motor movements & $1.66 \pm 1.37$ & $2.28 \pm 1.51$ & -1.602 & 0.109 \\
\hline Other & $0.75 \pm 0.67$ & $2.75 \pm 1.50$ & -4.921 & $<0.001$ \\
\hline NES total & $4.70 \pm 2.52$ & $9.0 \pm 4.09$ & -3.824 & $<0.001$ \\
\hline
\end{tabular}

SLD: specific learning disorder; BIF: borderline intellectual functioning.

Values are given as mean and standard deviation.

Table 7. Relationship between NES scores and FSIO

\begin{tabular}{|l|c|c|c|c|}
\hline NES subscales & $\begin{array}{c}\text { FSIQ(SLD) } \\
\text { (Corr. Coefficient) }\end{array}$ & $P$ & $\begin{array}{c}\text { FSIQ (BIF) } \\
\text { (Corr. Coefficient) }\end{array}$ & $P$ \\
\hline Sensory integration & -0.399 & 0.029 & -0.336 & -0.700 \\
\hline Motor coordination & -0.194 & 0.303 & -0.188 & 0.320 \\
\hline Complex motor movements & -0.013 & 0.947 & -0.036 & 0.848 \\
\hline Other & -0.122 & 0.522 & -0.082 & 0.667 \\
\hline NES total & -0.160 & 0.399 & -0.211 & 0.263 \\
\hline
\end{tabular}

NES: Neurological Evaluation Scale; FSIQ: Full Scale Intelligence Quotient. 


\section{Discussion}

In this study, cognitive test performances, minor neurological symptom presence and emotion regulation difficulties of children with SLD and BIF were compared. According to the findings of the study, there was no significant difference between the two groups in the Gessell Figure Drawing Test, the Bender Gestalt visual motor integration test and the GISD-B form test. ERS emotional regulation subscale scores of the SLD group were found to be better. In NES, statistically significant difference was found between the groups except for the complex motor movements subscale, and the performance of the SLD group was shown to be better.

It has been reported that children with SLD have worse performance in tests of visual perceptual development (such as the Gessell test) than healthy children. In our study, $26.6 \%$ of the SLD group and $13.3 \%$ of the BIF group were found successful in the test of the child Gessell Figure Drawing Test. Identified in this study to SLD 73.4\% failure rate is consistent with literature ${ }^{28,29}$. No statistically significant difference was found between the two groups. In this respect, it is estimated that the distinction between the two diagnoses cannot be made. However, no literature information was available for testing Gessell Figure Drawing Test for BIF.

The Bender Gestalt test was applied to compare visual motor integration skills between the two groups. Previous studies have found a relationship between intelligence level and Bender Gestalt test scores $^{27}$. Similarly, children with SLD have been shown to have worse test performance than non-SLD children ${ }^{30}$. There was no statistically significant difference in Bender Gestalt test performances between two diagnostic groups in our study. The groups showed similar performance in terms of visual motor integration.

Another area in which two groups are compared is the GISD-B form results. In previous studies, GISD-B test performance of children with SLD was found to be lower than that of healthy children ${ }^{28,29}$. There is no study done with GISD-B test in BIF ones. A statistically significant difference was not found, although we found that the SLD group had better performance in our study. Significant results can be obtained with this test battery in further studies with more cases.

There are no studies investigating the relationship between ERS and SLD or BIF. In our study, there was a difference in the emotion regulation subscale scores between the two groups. The SLD group has lower (better) subscale scores than the BIF group. No statistical difference was found for ERS total score and for the lability/negative subscale scores. In addition, in other analyzes of subscales, there was a negative correlation between PSIQ and FSIQ and emotion regulation subscale scores in SLD cases. When these two findings are combined, it can be considered that the emotion regulation skill is directly related to the FSIQ, and the negative correlation with the PSIQ decreases in the SLD patients, resulting in a statistical difference between the two diagnoses. One of the main aims of this study is the search for an additional evaluation method that can be used in the differential diagnosis of SLD and BIF. We can say that the emotion regulation subscale of the ERS can be used for this purpose.

There was no significant difference between the two groups in terms of variability-negativity subscale. McClure et al. ${ }^{31}$ reported that, emotional adjustment is directly related to the level of intelligence, while other areas of emotion (such as understanding their own feelings, recognizing others' emotions, facial expressions) are not clearly associated with intelligence. The similarity of lability/ negativity subscale scores between the two groups in our study is consistent with this review.

In the literature MNS is associated with many psychiatric disorders, academic and behavioral problems. There are no studies investigating the frequency of MNS in BIF cases or the relationship between MNS and intelligence. In a study comparing the SLD, $\mathrm{ADHD}$, and SLD + ADHD groups with the controls, it was reported that MNS frequency was higher than healthy group ${ }^{32}$. In our study, NES was used to reveal the frequency of MNS in BIF and SLD cases. Sensory integration, motor coordination and NES total scores were found significantly higher in the BIF group than in the SLD group. There was no correlation between the subscales and the FSIQ in the BIF group, while there was a negative correlation between the sensory integration and the FSIQ in the SLD group. There was no correlation between NES scores and VSIQ and PSIQ.

As with the ERS, it means that the SLD group which have higher FSIQ scores has better performance in NES than BIF. In other words, it turns out that the NES scale can be predictive of the distinction between these two identities. Perhaps even more meaningful than this finding is that the NES scores are also valuable for prognostic evaluation in cases of complex diagnosis. The basis of this statement is that the presence of minor neurologic symptoms in psychiatric illnesses is associated with a worse neuropsychological profile in these patients. As MNS increase, executive functions, visual and verbal memory performance have been shown to decrease ${ }^{32-34}$.

The main limitation of our study is that assessors are not blind to the diagnosis of patients. At the same time, even if they are evaluated free from psychotropic or similar medical treatment, it is a limitation of not excluding ADHD in both SLD and BIF groups. Another limitation of this study was the selection of consecutive patients who applied to the outpatient clinic and the randomization procedure was not performed and lack of a control group.

In summary, there is frequent diagnostic confusion due to the fact that they have very few studies and very few diagnostic tools related to SLD and BIF which are the frequently diagnosed identities in child and adolescent psychiatry outpatient clinics. Symptoms of BIF and SLD occur with formal education and the similarity of the pre-markers in retrospective questionnaires related to the pre-school period may lead to diagnostic confusion. Among the scales used in this study, it was found that the emotion regulation subscale scores of the ERS and sensory integration, motor coordination, and total scores of the NES can be used for both discrimination and prognostic evaluation of these two diagnoses.

\section{References}

1. Fidan T. Assessment of mental symptoms and risk factors in children and adolescents who admitted to the child-adolescent psychiatry clinic. Konuralp Med J. 2011;3(1):1-8.

2. Turkoglu S. Diagnosis of patients referring to a child and adolescent psychiatry outpatient clinic. Selcuk Tip Derg. 2014;30(3):118-22.

3. Durukan İ, Karaman D, Kara K, Türker T, Tufan AE, Yalçın Ö, et al. Diagnoses of patients referring to a child and adolescent psychiatry outpatient clinic. Dusunen Adam. 2011;24(2):113-20.

4. Salvador-Carulla L, García-Gutiérrez JC, Ruiz Gutiérrez-Colosía M, Artigas-Pallarès J, García Ibáñez J, González Pérez J, et al. Borderline intellectual functioning: consensus and good practice guidelines. Rev Psiquiatr Salud Ment. 2013;6(3):109-20.

5. Hassiotis A, Strydom A, Hall I, Ali A, Lawrence-Smith G, Meltzer H, et al. Psychiatric morbidity and social functioning among adults with borderline intelligence living in private households. J Intellect Disabil Res. 2008;52(Pt 2):95-106.

6. Gigi K, Werbeloff N, Goldberg S, Portuguese S, Reichenberg A, Fruchter $\mathrm{E}$, et al. Borderline intellectual functioning is associated with poor social functioning, increased rates of psychiatric diagnosis and drug use--a cross sectional population based study. Eur Neuropsychopharmacol. 2014;24(11):1793-7.

7. Emerson E, Einfeld S, Stancliffe RJ. The mental health of young children with intellectual disabilities or borderline intellectual functioning. Soc Psychiatry Psychiatr Epidemiol. 2010;45(5):579-87.

8. American Psychiatric Association. Diagnostic and Statistical Manual of Mental Disorders, 4th edition, text revision. Washington, DC: American Psychiatric Association; 2000.

9. American Psychiatry Association, Diagnostic and Statistical Manual of Mental Disorders, 5th edition. Arlington, VA: American Psychiatric Association; 2013.

10. Silver LB. Developmental learning disorder. In: Lewis M, editor. Child and adolescent psychiatry textbook. 3rd ed. Philadelphia: Lippincott Williams \& Wilkins; 2002. p. 621-9. 
11. Lewis C, Hitch GJ, Walker P. The prevalence of specific arithmetic difficulties and specific reading difficulties in 9- to 10-year-old boys and girls. J Child Psychol Psychiatry. 1994;35(2):283-92.

12. Rutter M, Caspi A, Fergusson D, Horwood LJ, Goodman R, Maughan B, et al. Sex differences in developmental reading disability: new findings from 4 epidemiological studies. JAMA. 2004;291(16):2007-12.

13. Shafer SQ, Shaffer D, O'Connor PA, Stokman CJ. Hard thoughts on neurological soft signs. In: Rutter M, editor. Developmental neuropsychiatry. New York: Guilford Press; 1983. p. 133-43.

14. Dazzan P, Morgan KD, Chitnis X, Suckling J, Morgan C, Fearon P, et al. The structural brain correlates of neurological soft signs in healthy individuals. Cereb Cortex. 2006;16(8):1225-31.

15. Manschreck TC, Ames D. Neurologic features and psychopathology in schizophrenic disorders. Biol Psychiatry. 1984;19(5):703-19.

16. Sanders RD, Keshavan MS, Forman SD, Pieri JN, McLaughlin N, Allen $\mathrm{DN}$, et al. Factor structure of neurologic examination abnormalities in unmedicated schizophrenia. Psychiatry Res. 2000;95(3):237-43.

17. Graziano PA, Reavis RD, Keane SP, Calkins SD. The role of emotion regulation in children's early academic success. J Sch Psychol. 2007;45(1):3-19.

18. Fujiki M, Brinton B, Clarke D. Emotion regulation in children with specific language impairment. Lang Speech Hear Serv Sch. 2002;33(2):102-11.

19. Wechsler D. Manual for the Wechsler Intelligence Scale for Children WISC-R. New York: Psychol Corp; 1974.

20. Savasir I, Sahin N. Wechsler Cocuklar Için Zeka Olcegi (WISCR) El Kitabi. Turk Psikologlar Dernegi Yayinlari. Ankara; 1995.

21. Heinrichs DW, Buchanan RW. Significance and meaning of neurological signs in schizophrenia. Am J Psychiatry. 1988;145(1):11-8.

22. Shields A, Cicchetti D. Emotion regulation among school-age children: the development and validation of a new criterion Q-sort scale. Dev Psychol. 1997;33(6):906-16.
23. Kapci EG, Uslu R, Akgun E, Acer D. Psychometric properties of the Turkish adaptation of the emotion regulation checklist. Turk J Child Adolesc Men Health. 2009;16(1):13-20.

24. Koppitz EM. The Visual Aural Digit Span Test. New York: Grune and Statton; 1963.

25. Karakas S, Yalin A. Visual Aural Digit Span Test Form B (GISD-B). Ankara: Medikomat; 1993.

26. Karakas S, Yalin A. Normative study of Visual Aural Digit Span Test Form-B on Turkish adolescents and adults (ages 13-54). Turk Psikoloji Dergisi. 1995;10(34):20-31.

27. Koppitz EM. The bender gestal test for young children. New York: Grune and Stratton; 1963.

28. Kayhan E. The relation between reading comprehension with vocabulary, visual perception and short term memory in 1-5th grade students [unpublished master thesis]. Ankara: Ankara University; 2010.

29. Turgut S, Erden G, Karakas S. The profiles of Specific Learning Disability (SLD), attention deficit hyperactivity disorder comorbid with SLD and control group through the SLD battery. Turki J Child Adolesc Ment Health. 2010;17(1):13-26.

30. Kap S, Zabci N. Comparative examination of psychological and cognitive functioning in children with learning disabilities. İstanbul; 2014.

31. McClure KS, Halpern J, Wolper PA, Donahue JJ. Emotion regulation and intellectual disability. J Develop Disab. 2009;15(2):38-44.

32. Tumkaya S, Karadag F, Oguzhanoglu NK. Neurological soft signs in schizophrenia and obsessive compulsive disorder spectrum. Eur Psychiatry. 2012;27(3):192-9.

33. Arango C, Bartko JJ, Gold JM, Buchanan RW. Prediction of neuropsychological performance by neurological signs in schizophrenia. Am J Psychiatry. 1999;156(9):1349-57.

34. Cuesta MJ, Peralta V, de Leon J. Neurological frontal signs and neuropsychological deficits in schizophrenic patients. Schizophr Res. 1996;20(1-2):15-20. 